\title{
Tendências Mundiais de Geração de Conhecimento e Propriedade Intelectual sobre - Microencapsulamento de Óleos Vegetais com Destaque para o Óleo de Café
}

\author{
Worldwide Trends in Knowledge Generation and Intellectual Property of \\ Microencapsulation of Vegetable Oils, Especially Coffee Oil
}

\author{
Julio Page de Castro \\ Carolina Vieira Viêgas ${ }^{2}$ \\ Lília Calheiros de Oliveira Barretto ${ }^{3}$ \\ Suely Pereira Freitas ${ }^{2}$ \\ ${ }^{1}$ Instituto Federal de Educação, Ciência e Tecnologia do Rio de Janeiro, Duque de Caxias, RJ, Brasil \\ ${ }^{2}$ Universidade Federal do Rio de Janeiro, Rio de Janeiro, RJ, Brasil \\ ${ }^{3}$ Universidade Federal de Sergipe, Aracaju, SE, Brasil
}

\begin{abstract}
Resumo
Os Óleos Vegetais (OVs) são utilizados por diferentes indústrias devido, principalmente, à presença de substâncias com potencial bioativo e sensorial. Os Óleos Vegetais e, entre eles, o óleo de café são susceptíveis à oxidação, o que reduz sua qualidade e seu tempo de prateleira. Uma das formas de preservar componentes dos OVs é por meio de seu microencapsulamento. O objetivo deste trabalho é identificar as tendências internacionais no microencapsulamento de OVs, em particular do óleo de café por meio de patentes depositadas em bases de dados nacionais e internacionais, além de artigos científicos publicados. Nos trabalhos analisados, os óleos microencapsulados foram destinados, principalmente, à alimentação (humana e animal), à indústria farmacêutica, à preservação de compostos bioativos, etc. Apesar de ser o maior produtor e exportador de café no mundo, o Brasil não apresentou tecnologia no quesito concessão de patentes, mas o país apresentou-se como o líder na publicação de artigos científicos relacionados ao uso microencapsulamento para preservação de OVs.
\end{abstract}

Palavras-chave: Propriedade Intelectual. Microencapsulamento. Óleo de Café.

\begin{abstract}
Vegetable oils and their components have historically been used by the food, textile, cosmetic and pharmaceutical industries, mainly due to the presence of substances with bioactive and sensory potential. Vegetable oils and, among them, coffee oil are susceptible to oxidation, which reduces their quality and shelf life. One of the ways of preserving the main components of vegetable oils is through their microencapsulation. This work aimed at identify the main international trends in the microencapsulation of vegetable oils, in particular coffee oil. The following keyword combinations were applied in the topic field of the consulted databases: (i) "microencapsulation" AND "vegetable oil"; (ii) "microencapsulation" AND "vegetable oil" AND "spray drying"; (iii) "vegetable oil" AND "spray drying" and (iv) "microencapsulation" AND "coffee oil", (v) "coffee oil" AND "spray drying" and (vi) "microencapsulation" AND "coffee oil" AND Spray drying. In the analyzed works, the microencapsulated oils were mainly intended for food (human and animal), pharmaceutical industry, preservation of bioactive compounds, cosmetics and polymers. Despite being the largest producer and largest exporter of coffee in the world, Brazil has no presented technology in the issue of patents but is the leader in the publication of scientific articles related to the use of microencapsulation for food/oil preservation.
\end{abstract}

Keywords: Intelectual Property. Microencapsulation. Coffee Oil.

Área Tecnológica: Engenharia de Alimentos. Produtos Naturais. Gestão Tecnológica. 


\section{Introdução}

Os Óleos Vegetais e seus componentes são, historicamente, utilizados pelas indústrias de alimentos, têxtil, cosmética e farmacêutica devido, principalmente, à presença de substâncias com potencial bioativo. Por se tratar de ingredientes naturais, essas matérias-primas são cada vez mais aplicadas na geração de novos produtos que atendem ao apelo de sustentabilidade, contribuindo para o fortalecimento da cadeia produtiva. Óleos, azeites e gorduras são substâncias de origem vegetal ou animal que consistem predominantemente em misturas de ésteres, oriundas de combinação de ácidos graxos com a glicerina, denominados triacilgliceróis encontrados na soja, na canola, na palma, na mamona, na linhaça, no café e em outros produtos (GUNSTONE, 2002). Os lipídeos são tipicamente compostos de triacilgliceróis, glicolipídeos, fosfolipídeos, lipoproteínas e ácidos graxos contendo entre 12 e 22 carbonos, podendo ser componentes uma mistura de ácidos graxos saturados, monoinsaturados e poli-insaturados que apresentam inúmeros benefícios para a saúde (LEHNINGER; NELSON; COX, 2014). Devido aos perfis de compostos voláteis identificados na fração lipídica do óleo de café torrado, este mostra-se potencialmente aplicável na indústria de alimentos como realçador de sabor devido ao seu aroma agradável e pronunciado (ARRUDA et al., 2012; MONDELLO et al., 2005; PAGE; ARRUDA; FREITAS, 2017). A fração lipídica do café apresenta, em geral, 75\% de triglicerídeos, $1 \%$ de ácidos graxos livres e até $19 \%$ de material insaponificável, sendo esta última composta principalmente de ésteres terpênicos, tocoferóis e esteróis, além de ceras e lipídeos polares (NIKOLOVA-DAMYANOVA; VELIKOVA; JHAM, 1998). Os principais ácidos graxos descritos por Folstar et al. (1985) para óleo de café da espécie C. arabica são: ácido mirístico $(0,2 \%)$ ácido palmítico (35,2 a 36,7\%), ácido esteárico (7,2 a 9,7\%), ácido oleico (9,5 a 11,9\%), ácido linoleico (41,2 a 42,6\%), ácido linolênico (1,3 a 2,7\%) e ácido araquidônico (0,3 a 1,5\%).

A maioria dos óleos comestíveis é instável quimicamente, susceptível à degradação oxidativa, especialmente quando expostos a oxigênio e à luminosidade, além de variações de umidade $e$ temperatura (GOULA; ADAMOPOULOS, 2012). Essa degradação oxidativa resulta em perda de qualidade nutricional, alteração de propriedades sensoriais e redução do tempo de prateleira. Uma vez que a aplicação direta dos Óleos Vegetais na formulação de produtos é um desafio devido ao propósito de preservação dos compostos bioativos, as indústrias alimentícia, cosmética e farmacêutica estão buscando soluções tecnológicas para alcançar uma forma de preservar estes compostos, assegurando ao mesmo tempo um impacto mínimo sobre as propriedades organolépticas e qualitativas dos produtos finais (ĐORĐEVIĆ et al., 2014).

O microencapsulamento é uma técnica robusta que permite a proteção de uma ampla gama de materiais de interesse bioativo e sensorial pela incorporação em uma matriz protetora (FRASCARELI; SILVA; TONON, 2012). Nesse sentido, a técnica de microencapsulamento de óleos vem sendo bastante utilizada para evitar a perda de compostos voláteis, bem como a degradação dos lipídeos e as interações indesejadas com outros ingredientes. Nas últimas décadas, diversos grupos de pesquisa em todo o mundo vêm estudando o microencapsulamento de diferentes óleos, como canela (VAIDYA et al., 2006), hortelã (BARANAUSKIENÉ et al., 2007), girassol (AHN et al., 2008), abacate (BAE; LEE, 2008), romã (ĐORĐEVIĆ et al., 2014), canola (SUN-WATERHOUSE; WANG; WATERHOUSE, 2014) e café (CARVALHO; SILVA; HUBINGER, 2014; GETACHEW; CHUN, 2016). 
O processo de microencapsulamento resulta em micropartículas formadas pelo óleo (núcleo) envolto pelo material de parede (encapsulante). Essa tecnologia não somente evita perdas e alterações químicas durante a produção e estocagem do alimento, como também resulta em um ingrediente versátil em forma de pó e com novas propriedades (FRASCARELI; SILVA; TONON, 2012).

As principais vantagens da aplicação do óleo microencapsulado em alimentos são o manuseio e a incorporação mais fáceis se comparado ao óleo in natura, além da possibilidade de liberação controlada dos ingredientes do núcleo durante o consumo (ADAMIEC; KALEMBA, 2006). Um importante desafio é encontrar um encapsulante adequado ao tipo de óleo usado, considerando as características emulsificantes, a capacidade de formação do filme da micropartícula, etc. Diversos tipos de compostos, como biopolímeros e nanopartículas, naturais ou não, vêm sendo amplamente utilizados como materiais de parede em processos de microencapsulamento de Óleos Vegetais (BARANAUSKIENÉ et al., 2007; FREIBERGER, 2015).

De acordo com Borschiver et al. (2014), a inovação é primordial para a sobrevivência das empresas, devendo ser considerada no processo de tomada de decisões. Os estudos prospectivos contribuem para a avaliação das principais tendências globais, mapeando desenvolvimentos científicos e tecnológicos capazes de influenciar, de forma significativa, uma indústria, a economia ou a sociedade como um todo (MAYERHOFF, 2008).

O objetivo deste trabalho é identificar as principais tendências internacionais no microencapsulamento de Óleos Vegetais, em particular do óleo de café por meio de uma análise de patentes depositadas em escritórios nacionais e internacionais e de artigos científicos publicados.

\section{Metodologia}

A metodologia aplicada para alcançar os objetivos deste trabalho foi conduzida por meio da análise do depósito de patentes, de artigos científicos e dos atores (empresas, centros de pesquisa e universidades) participantes do processo. A análise de patentes é utilizada para avaliação do impacto que um tema proporciona na inovação tecnológica para um intervalo de tempo estabelecido (BORSCHIVER et al., 2014). A análise de documentos de patentes depositadas, associada à inovação tecnológica, foi realizada por meio de registros coletados nas bases de dados Derwent Innovation Index ${ }^{\circledR}$ (Clarivate Analitytics - Web of Knowledge, 2019), no período de 1963 a maio de 2019 e na base do Instituto Nacional da Propriedade Industrial (INPI), via sítio on-line específico. Para a pesquisa dos artigos científicos, utilizou-se a plataforma Scopus, ferramenta de navegação que inclui a maior coleção mundial multidisciplinar de resumos, referências e índices da literatura científica e técnica (SCOPEL; GREGOLIN; FARIA, 2013), sendo estabelecidos os últimos sete anos (janeiro 2012 a maio 2019) como período de levantamento da evolução da produção científica.

Para elaborar esse levantamento, foram utilizadas, tanto para a busca e patentes quanto para a busca de artigos científicos, as seguintes combinações de palavras-chave: (i) "microencapsulation" AND "vegetable oil"; (ii) "microencapsulation" AND "vegetable oil" AND "spray drying"; (iii) "vegetable oil" AND "spray drying" e (iv) "microencapsulation" AND "coffee oil", (v) "coffee oil" AND "spray drying" and (vi) "microencapsulation" AND "coffee oil" AND "spray drying". Os termos em inglês foram utilizados para as bases internacionais, enquanto os termos 
em português foram utilizados para busca de documentos na base nacional do INPI. Foram considerados válidos os documentos que apresentaram esses termos no título e/ou no resumo.

O tratamento bibliométrico foi realizado em maio de 2019 com o auxílio do software Microsoft Excel (versão 2010) para análise dos dados de acordo como ano de depósito, depositantes (empresas, instituições ou pessoas físicas), países de origem e classificações da World International Property (WIPO) para a análise de patentes. Na pesquisa dos artigos científicos foram considerados ano de publicação, países de origem $e$ atores (universidades ou centros de pesquisa). Para ambos os tipos de análise (patentes e artigos), o tema principal abordado na publicação também foi avaliado (SHIA; SHEN; SUNC, 2017). Ainda, este trabalho não considerou o período de sigilo de 18 meses das patentes.

\section{Resultados e Discussão}

Os principais resultados deste trabalho serão mostrados e discutidos nas seções deste tópico.

\subsection{Propriedade Intelectual}

Após as buscas realizadas na base de dados Derwent Innovations Index, 721 patentes foram relacionadas com as palavras-chave aplicadas. Após uma análise criteriosa, apenas 13 patentes apresentaram correlação com o tema microencapsulamento de óleo vegetais. A primeira etapa realizada foi a organização dos pedidos de patentes por Classificação Internacional. Essa organização se deve ao fato de que este trabalho não tem como objetivo a seleção de uma tecnologia específica, mas identificar os pedidos de patente que estejam envolvidos com o tema de "microencapsulamento de Óleos Vegetais".

A Figura 1 ilustra as porcentagens das patentes analisadas por códigos de classificação internacional, levando-se em consideração apenas a primeira letra (seção) e dezena (classe). Essa divisão seguiu o disposto na Classificação Internacional de Patentes (International Patent Classification - IPC), conforme estabelecida no Acordo de Estrasburgo, em 1971, com última atualização em 2012.

Figura 1 - Distribuição dos códigos de CIP

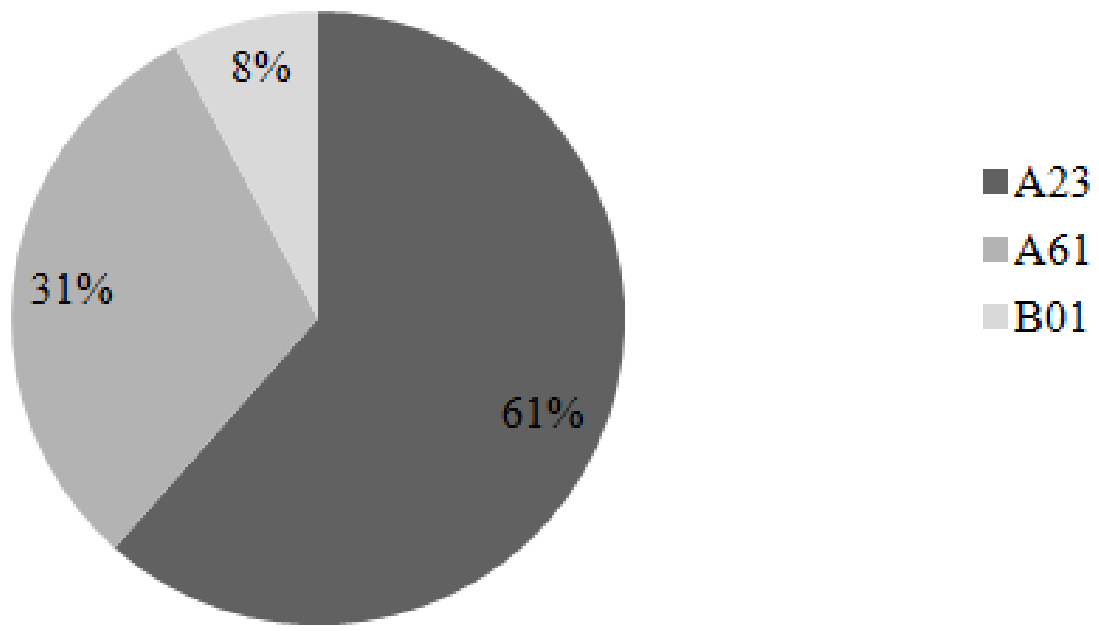

Fonte: Elaborada pelos autores deste artigo (2019) 
Esta pesquisa revelou que $61 \%$ das patentes estão classificadas como A23 dos documentos analisados inseridos na área de produtos alimentícios e seu beneficiamento; café, chás e sua manufatura; tratamento físico e conservação. A segunda classe com maior número de depósitos foi a classe A61 (preparações para produtos farmacêuticos) com $31 \%$ das patentes pesquisadas, reforçando a aplicação de matérias-primas com propriedades sensoriais e bioativas nas indústrias de alimentos e de cosméticos. O terceiro código de classificação internacional mais expressivo foi o B01 (processos químicos ou físicos, por exemplo, catálise, química coloidal; aparelhos pertinentes a eles) com apenas uma (1) patente pertencente a este grupo representando $8 \%$ de relevância.

Entre os principais óleos encapsulados, destacam-se o de girassol, a palma, o abacate, a soja, o gergelim, o amendoim, o arroz, o milho, a linhaça, o cártamo, a colza, a amêndoa, a noz, a avelã, o coco e o azeite de oliva. As patentes que utilizaram o óleo de café como material de núcleo representam apenas $6,6 \%$ dos documentos analisados.

Os principais materiais de parede encontrados foram caseinato de sódio, cálcio, albumina, lactoalbumina, iactoglobulina, gelatina, soja e tapioca. Os agentes emulsionantes, como a goma xantana, goma antártica e carragenina, amido de milho, mandioca, batata e trigo, merecem destaque. O spray drying destaca-se como a técnica mais utilizada para o microencapsulamento da mistura óleo, material encapsulante com propriedades emulsificantes, em meio aquoso.

A formação de uma emulsão estável na mistura do óleo com material de parede em meio aquoso é decisivo para garantir a eficiência do microencapsulamento. Por se tratar de meios com polaridades opostas (óleo apolar e meio aquoso polar), uma emulsão estável irá permitir a formação de micropartículas homogêneas quando a mistura for distribuída na forma de gotículas no interior do spray drying no processo de secagem. Partículas oriundas de emulsões de baixa estabilidade são mais propícias a apresentar ranhuras na superfície e, portanto, são mais susceptíveis à difusão de oxigênio para o núcleo, atingindo o óleo e promovendo sua oxidação (REINECCIUS;YAN, 2015).

A Figura 2 mostra a evolução temporal no depósito de patentes relacionadas à preservação de Óleos Vegetais onde é possível perceber que o interesse por parte dos depositantes mostrou um crescimento no período de 2016 a 2019, sendo os anos de 2016 e 2018 os que apresentaram uma maior concentração de patentes. Os números de 2018 e 2019 ainda podem aumentar, devido ao período de sigilo.

Figura 2 - Evolução do número de patentes depositadas referentes à inovação tecnológica aplicada à preservação de Óleos Vegetais por meio de microencapsulamento entre 1974 e 2019

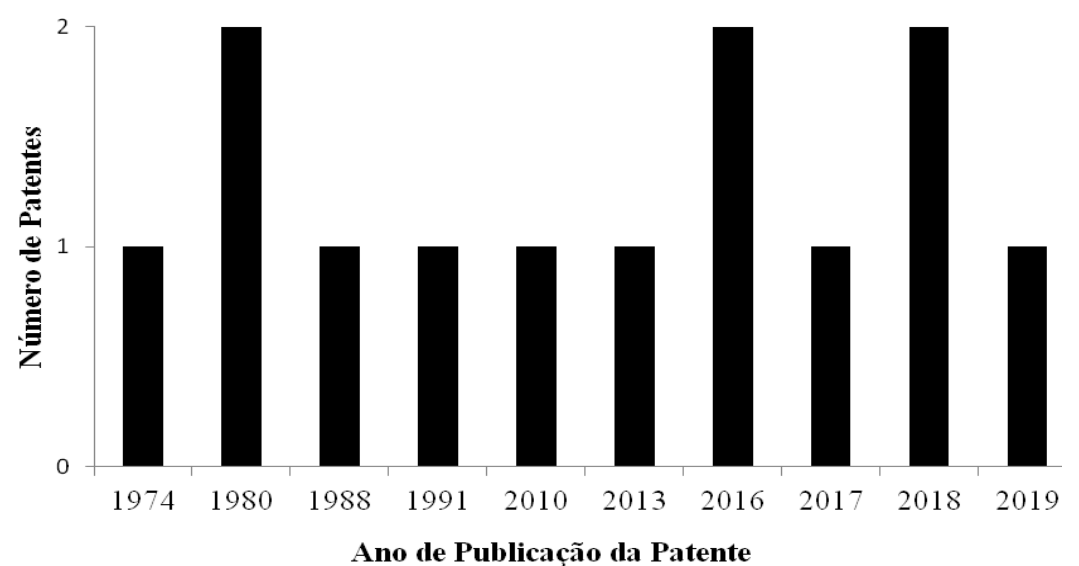

Fonte: Elaborada pelos autores deste artigo (2019) 
Com relação à origem das patentes concedidas, de modo a identificar os países que mais direcionaram esforços quanto à aplicação das técnicas de preservação de Óleos Vegetais por meio do microencapsulamento (Figura 3), a China foi o país líder, com cerca de $45 \%$ dos documentos analisados e todas as patentes desse país foram depositadas entre 2010 e 2016 . Essa participação relevante pode ser justificada pelo protagonismo da China na economia mundial nos últimos anos, o que perpassa por um processo de forte investimento em ciência e tecnologia (SHIA; SHEN; SUNC, 2017). O Brasil não apresentou nenhuma patente depositada com os temas da pesquisa.

Figura 3 - Origem das patentes concedidas

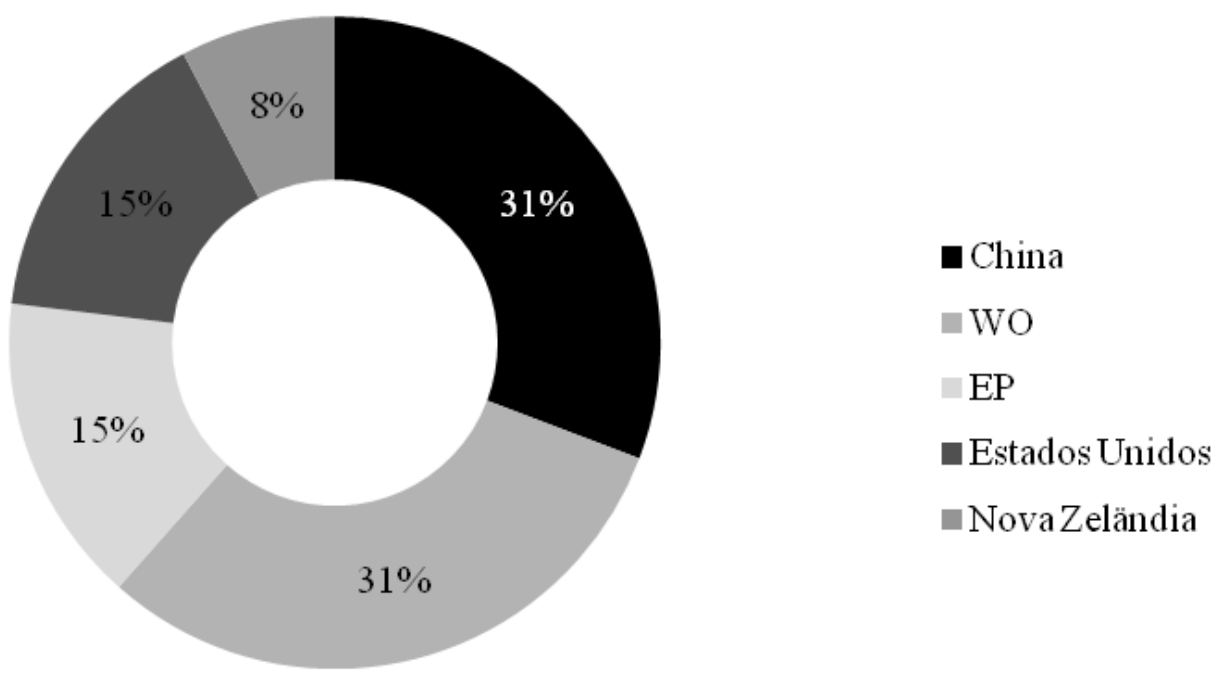

Nota: EP: European Patent Office com World Intellectual Property Organization (WIPO).

Fonte: Elaborada pelos autores deste artigo (2019)

A participação expressiva da iniciativa privada, como detentora de depósito, mostra que o tema pesquisado apresenta grande relevância devido às perspectivas de potencial de exploração comercial. Das 13 patentes selecionadas, apenas uma foi depositada por uma universidade, a Universidade South China Technology. A empresa de origem australiana Clover Corp Ltd. se destacou com dois pedidos depositados nos anos de 2013 e 2017. Ambas as patentes estão relacionadas com a técnica de microencapsulamento para preservação de óleos e bioativos para formulação de produtos estáveis destinados ao consumo humano e animal, bem como na formulação de suplementos alimentares e produtos farmacêuticos.

De acordo com o protocolo depositado por Patch et al. (2013), a formulação de alimentos funcionais compreende uma mistura de componentes de proteína (caseína, soja, soro de leite, gelatina, ovo, albumina, proteínas de algas, leveduras ou fontes fúngicas), lípidos, (incluindo gorduras, ceras e esteróis, constituídos por óleo vegetal, óleo de peixe e/ou gorduras animais) e carboidratos, consistindo em monossacarídeo, dissacarídeo, trissacarídeo, oligossacarídeo, maltodextrinas, maltodextrinas resistentes, amido, materiais derivados do amido, xarope de glicose, sólidos de xarope de glicose ou mel. Também são adicionados compostos solúveis em óleo como as vitaminas A, D, E, K, tocoferóis e betacaroteno como substâncias bioativas.

De acordo com o mesmo protocolo, o microencapsulamento dos Óleos Vegetais retarda a degradação dos compostos bioativos e protege os ácidos graxos insaturados frente à oxidação, prolongando, assim, o tempo de consumo e mantendo suas propriedades de interesse. As 
micropartículas à base de proteínas possuem uma forte capacidade de proteger o óleo contra a oxidação para torná-las adequadas ao uso em sistemas alimentares líquidos/semilíquidos. Entretanto, se o interesse no microencapsulamento do óleo estiver relacionado aos compostos voláteis responsáveis pelo aroma, além das perdas por evaporação durante o processo de secagem, é possível que estas ocorram por reação com o próprio material de parede. Compostos voláteis são, em sua maioria, mais reativos (baixa estabilidade), bem como as proteínas devido à variedade de grupos funcionais que possuem como os próprios grupos amino. Nesse caso, esse pode ser um fator limitante na escolha do material de parede de base proteica para o microencapsulamento de substâncias características de aroma (REINECCIUS; YAN, 2015).

De acordo com o protocolo depositado por Wang et al. (2017), o microencapsulamento auxilia na preservação de óleos que contenham ácidos graxos poliinsaturados de cadeia longa, como os ácidos eicosapentaenóico, docosapentaenóico, alfa-linolênico, linoleico, gama-linolênico, estearidônico e linoleico conjugado. Uma vez que o óleo de café possui uma grande variedade de compostos voláteis e fenólicos, que, por conseguinte, apresentam elevada capacidade antioxidante, a tecnologia de microencapsulamento apresenta-se como uma estratégia viável para preservação dessas moléculas, conforme o que está descrito no protocolo depositado por Patch et al. (2013).

O Brasil não apresentou nenhuma patente depositada no período analisado na busca realizada na plataforma do INPI entre abril e maio de 2019 por meio das mesmas combinações de palavra-chave apresentadas na metodologia. No âmbito da Ciência e Tecnologia de Alimentos, destaca-se como a principal grande área de conhecimento das patentes analisadas com diferentes aplicações do óleo microencapsulado como os destinados à alimentação (humana e animal), indústria farmacêutica, preservação de compostos bioativos, cosmética e polímeros.

Muitas patentes têm como objetivo principal a preservação da estabilidade dos materiais ativos durante o processamento de alimentos. Devido à instabilidade oxidativa dos Óleos Vegetais, o protocolo de Luo, Liu e Qin (2018) descreve o método de peparação desses óleos em forma de pó com o intuito de aumentar a vida útil dos alimentos a partir do microencapsulamento. Após o processo de microencapsulamento, espera-se um aumento na estabilidade de armazenamento com redução de $34 \%$ da oxidação do produto comparado ao óleo vegetal in natura. Entre os óleos descritos nessa patente, estão incluídos alguns Óleos Vegetais comestíveis, como o de camélia, soja, milho, gergelim, amendoim e colza. Os agentes encapsulantes empregados foram amido de milho, trigo, tapioca, batata e batata-doce.

Apenas uma patente foi relatada utilizando o microencapsulamento do óleo de café, com finalidade de uso em produtos para cuidados pessoais e alimentos (CANHAM; LONI; QURRAT, 2010). Já a patente depositada por Zeller, Chang e Norbury (1987) apresentou a utilização de Óleos Vegetais microencapsulados (por exemplo, óleo de mamona e óleo de jojoba) com foco em aplicações cosméticas (emoliente) com espessantes poliméricos e encapsulados por um invólucro polimérico.

Materiais poliméricos solúveis em óleos permitem formar, no microencapsulamento, estruturas de maior tamanho com a preservação dos compostos presentes nos Óleos Vegetais e também contribuem com a aderência do óleo sob a pele. De acordo com o registro de Hernandez e Rivera (2019), o microencapsulamento dos óleos e proteínas vegetais é destinado para diversos setores da indústria. Outros usos dos Óleos Vegetais puderam ser observados nesses trabalhos, como os destinados para suplementação animal, conforme os descritos nas patentes 
de protocolos US4217370 e US4216234, ambas de Rawlings e Procter (1980a; 1980b) desenvolvidas pela Blue Wing Corp.

Esta prospecção tecnológica apresentou o cenário de patentes aplicadas ao microencapsulamento de Óleos Vegetais com diferentes finalidades. O Brasil, apesar de ser um grande produtor de Óleos Vegetais, não se destaca entre os depositantes. Mesmo sendo o maior produtor de café do mundo, houve apenas um depósito sobre o óleo de café na pesquisa realizada. Esse fato aponta para a necessidade de maiores investimentos em inovação por parte das universidades e de órgãos de fomento à pesquisa quanto ao desenvolvimento de invenções patenteáveis correlacionadas com o tema. Destacando os atores desse processo, a empresa de origem australiana Clover Corp Ltd. se destacou com dois pedidos depositados no ano de 2013 e 2017. A Universidade South China Technology foi o único centro acadêmico com patente depositada.

\subsection{Produção Científica}

Considerando a quantidade de artigos por ano, observou-se um crescimento acentuado do número de publicações nos anos de 2015 e 2016, com média de 32 documentos em cada ano, provenientes predominantemente de universidades e de instituições de pesquisa brasileiras $e$ estrangeiras. A quantidade de artigos científicos (157), obtidos com as mesmas combinações de palavras-chave, é consideravelmente superior quando comparada ao número de 13 patentes depositadas.

Como apresentado na Figura 4, as pesquisas científicas sobre microencapsulamento apresentam um perfil regional de equilíbrio entre os países da América do Sul, Europa e Ásia/Oceania com uma contribuição em torno de $30 \%$ de cada um desses blocos de países nas publicações reportadas entre janeiro de 2012 e março de 2019. O Brasil foi o grande promotor das divulgações científicas com um total de 36 artigos publicados nesse período, seguido da Índia (17), França (11) e Argentina, com 10 publicações. A China, país líder no depósito de patentes (46\%), apresentou a publicação de 11 artigos científicos, mesmo número de publicações da França.

Figura 4 - Distribuição de artigos científicos por continente

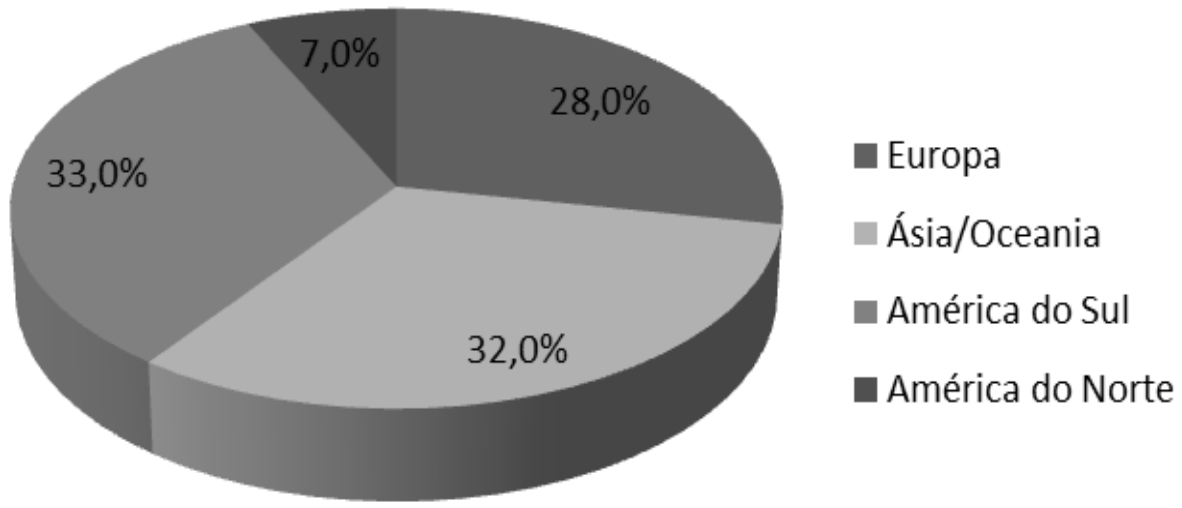

Fonte: Elaborada pelos autores deste artigo (2019)

Entre os assuntos predominantes abordados pela literatura, destacam-se os artigos sobre propriedades estruturais das micropartículas, materiais de parede e características de microen- 
capsulamento de Óleos Vegetais diversos por spray drying, o microencapsulamento de óleo de café com 13 artigos, além de reviews sobre microencapsulamento, com dez trabalhos.

Salienta-se que, a partir da busca das palavras-chave aplicadas neste estudo, diversos artigos científicos e patentes abordavam sobre as tecnologias de preservação de alimento por diferentes métodos de secagem: liofilização, secagem por convecção, etc. Como tais estudos e tecnologias não tratavam diretamente sobre spray drying e microencapsulamento, não foram incluídos nesta discussão. Entretanto, destaca-se que o panorama da indústria de alimentos, potencialmente, apresenta pesquisa e desenvolvimento tecnológico na busca da preservação de alimentos e resíduos, de forma a promover uma gestão agroindustrial eficiente e ambientalmente satisfatória.

\subsection{Atores do Processo - Produção Científica}

As universidades que mais publicaram artigos sobre o tema em questão foram a Unicamp (Brasil) e a Toulouse University (França), com sete publicações cada. O departamento de Engenharia de Alimentos da Unicamp estudou o microencapsulamento de café torrado e café verde em quatro artigos. Um dos artigos publicados pela faculdade de engenharia de alimentos da Unicamp teve como objetivo avaliar a influência das condições do processo de microencapsulamento do óleo de café torrado por spray drying utilizando goma arábica como material encapsulante. Os pesquisadores concluíram que a eficiência de encapsulamento do óleo de café é negativamente influenciada com o aumento da concentração de óleo e com o aumento da temperatura de ar de entrada do secador (spray drying). Por outro lado, a eficiência é aumentada com a quantidade de sólidos, que pode ser relacionada com a viscosidade da emulsão, que é um fator muito importante na eficiência do microencapsulamento de óleos (FRASCARELI; SILVA; TONON, 2012).

O mesmo grupo de pesquisadores do departamento de engenharia de alimentos da Unicamp realizou o microencapsulamento do óleo de café com a combinação de: i) goma arábica; ii) proteína de soro de leite; e iii) mistura de maltodextrina com proteína de soro de leite como materiais de parede. Por meio de isotermas de sorção, os pesquisadores concluíram que o óleo de café microencapsulado com goma arábica foi o que apresentou maior teor de absorção de água. Nesse caso, quanto menor a absorção de água, melhor o efeito do microencapsulamento e menor a chance do núcleo microencapsulado (no caso o óleo de café) em sofrer oxidação.

Os autores reportaram que o óleo microencapsulado com a combinação de maltodextrina e proteína de soro de leite apresentou maior eficiência, contribuindo com maior estabilidade à oxidação e, consequentemente, maior tempo de prateleira do óleo de café e suas propriedades sensoriais e bioativas de interesse (FRASCARELI; SILVA; TONON, 2012) . Nos artigos da Unicamp que abordaram sobre o microencapsulamento de café verde, os pesquisadores também avaliaram diferentes combinações de materiais de parede e condições de processamento via spray drying. A combinação de amido modificado Hi-cap com maltodextrina mostrou-se como a mistura mais eficiente de material de parede em relação à estabilidade oxidativa do óleo microencapsulado (CARVALHO; SILVA; HUBINGER, 2014; SILVA; VIEIRA; HUBINGER, 2014).

A Agroindustrial Chemistry Laboratory da Toulouse University publicou três artigos relacionados ao microencapsulamento de Óleos Vegetais, enquanto o Laboratory of Agro-Industrial Chemistry, da mesma universidade, publicou quatro trabalhos entre 2012 e 2014. O destaque foi para este último laboratório que, além de ter publicado um artigo de revisão sobre microen- 
capsulamento de proteínas vegetais em geral, focou em três artigos no estudo das condições operacionais e combinação de materiais encapsulantes para o microencapsulamento de alfa tocoferol obtido de diferentes fontes, por exemplo, da flor de girassol. É importante ressaltar que os pesquisadores realizam testes prévios sobre a estabilidade das emulsões formadas pela mistura do "material a ser encapsulado" + "água" + "encapsulante", uma vez que emulsões não estáveis resultam, em geral, em baixa eficiência de encapsulamento (NESTERENKO et al., 2012; NESTERENKO et al., 2013). O centro de pesquisa Central Institute of Fisheries Technology, na Índia, destacou-se com cinco publicações sobre microencapsulamento de óleo de peixe, rico em ômega 3. A universidade de Córdoba, na Argentina, teve participação com quatro publicações entre 2014 e 2016 sobre microencapsulamento de Óleos Vegetais e a University of Buenos Aires publicou dois artigos sobre microencapsulamento de óleo de peixe. Por sua vez, a University of Putra Malaysia publicou cinco trabalhos na área com diferentes matrizes vegetais. $\mathrm{Na}$ China, principal ator no processo de depósito de patentes, nenhum dos 11 artigos publicados (entre 2012 e 2019) está relacionado aos depositantes das patentes desse mesmo país.

Apesar de o Brasil ser o maior produtor e exportador de café do mundo, nas plataformas Derwent e INPI não foram encontradas patentes com as palavras-chave utilizadas na prospecção. Esse fato requer maior atenção por parte dos centros de pesquisas, universidades $e$ instituições de fomento quanto ao desenvolvimento de invenções patenteáveis correlacionadas com o referido tema.

\section{Considerações Finais}

O microencapsulamento de Óleos Vegetais, em particular do óleo de café, vem sendo estudado pelas universidades e centros de pesquisa pelo mundo, no entanto, esses estudos ainda são modestos em relação à geração de propriedade intelectual. A Ciência e Tecnologia de Alimentos destaca-se como a principal área cujas patentes analisadas estão relacionadas. Tais patentes apresentam diferentes aplicações de óleos microencapsulados destinados, principalmente, à alimentação (humana e animal), à indústria farmacêutica, à preservação de compostos bioativos, à cosmética e aos polímeros. A China destacou-se como o principal país depositante com protagonismo para empresas privadas como detentoras das patentes depositadas. As principais classes de códigos de classificação internacional de patentes foram o A23 (Produtos alimentícios e seu beneficiamento; café, chás e sua manufatura; tratamento físico e conservação) com $61 \%$ das patentes analisadas, seguida da classe A61 (Preparações para produtos farmacêuticos) com $30 \%$ das patentes analisadas.

Neste trabalho foram analisados 157 artigos científicos na base de dados Scopus. O Brasil se destacou com a publicação de 36 artigos, e as universidades com o maior número de publicações foram a brasileira Unicamp, de Campinas, SP, e a Universidade de Toulouse, na França, ambas com sete publicações no período estudado.

Apesar de ser o maior produtor e o maior exportador de café no mundo, o Brasil não apresenta tecnologia no quesito concessão de patentes, mas, por outro lado, o país se apresenta como o líder na publicação de artigos científicos relacionados ao uso de microencapsulamento para preservação de alimentos/óleos. 
O Brasil é o segundo maior consumidor de café do mundo com destaque no processamento em grande escala de café solúvel. Essa alta industrialização do café solúvel gera uma quantidade expressiva do coproduto que é a borra de café. Como o óleo pode ser obtido tanto do café torrado quanto da borra, é preciso potencializar a capacidade científica brasileira na busca de soluções tecnológicas para a destinação de resíduos agroindustriais, uma vez que esse setor apresenta grande protagonismo para a economia do país. Existe uma grande área pouco explorada que visa à aplicação comercial da borra de café para a recuperação de óleos, substâncias características do aroma e compostos bioativos.

A indústria nacional e a comunidade acadêmica devem estar atentas a esse setor que tanto influencia na economia brasileira, observando oportunidades de desenvolvimento e evolução constantes, sobretudo na transformação de pesquisas acadêmicas em inovação tecnológica. O microencapsulamento é um tipo de tratamento do óleo vegetal/óleo de café que pode proporcionar um aumento do potencial produtivo e do incentivo à inovação tecnológica na agroindústria e na valorização dos seus resíduos.

\section{Referências}

ADAMIEC, J.; KALEMBA, D. Analysis of microencapsulation ability of essential oils during spray drying. Drying Technology, [s.l.], v. 24, n. 9, p. 1.127-1.132, 2006.

AHN, J. H. et al. Optimization of microencapsulation of seed oil by response surface methodology. Food Chemistry, [s.l.], v. 107, n. 1, p. 98-105, 2008.

ARRUDA, N. P. et al. Correlação entre precursores e voláteis em café arábica brasileiro processado pelas vias seca, semiúmida e úmida e discriminação através da análise por componentes principais. Química Nova, [s.l.], v. 35, n. 10, p. 2.044-2.051, 2012.

BAE, E. K.; LEE, S. J. Microencapsulation of avocado oil by spray drying using whey protein and maltodextrin. Journal of Microencapsulation, [s.l.], v. 25, n. 8, p. 549-560, 2008.

BARANAUSKIENÉ, R. et al. Flavor retention of peppermint (Mentha piperita L.) essential oil spraydried in modified starches during encapsulation and storage. Journal of Agricultural and Food Chemistry, [s.l.], v. 55, n. 8, p. 3.027-3.036, 2007.

BORSCHIVER, S. et al. Roadmap tecnológico sisal. International Symposium on Technological Innovation, Aracaju, 2014.

CANHAM, L.; LONI, A.; QURRAT, S. U. A. Intrinsiq Materials Global Ltd. e Psimedica Ltd.

Consumer care or food composition e.g. toothpaste comprises mesoporous microparticulate material, at least some of pores of which are loaded with ingredient, where loaded mesoporous microparticulate material is encapsulated by capping layer. WO2010038064-A1, 8 Abr. 2010. Disponível em: https://apps.webofknowledge.com. Acesso em: 10 maio 2019.

CARVALHO, A. G. S.; SILVA, V. M.; HUBINGER, M. D. Microencapsulation by spray drying of emulsified green coffee oil with two-layered membranes. Food Research International, [s.l.], v. 61, p. 236-245, 2014.

ĐORĐEVIĆ, V. et al. Trends in Encapsulation Technologies for Delivery of Food Bioactive Compounds. Food Engineering Reviews, [s.l.], v. 7, n. 4, p. 452-490, 2014. 
FOLSTAR, P. Lipids. 1. ed. London; New York: Elsevier; Applied Science, 1985.

FRASCARELI, E. C.; SILVA, V. M.; TONON, R. V. Original article Determination of critical storage conditions of coffee oil microcapsules by coupling water sorption isotherms and glass transition temperature. International Journal of Food Science and Technology, [s.l.], v. 47, p. 1.044-1.054, 2012.

FREIBERGER, E. Encapsulation of Roasted Coffee Oil in Biocompatible Nanoparticles. Lebensmittel-Wissenschaft und-Technologie, [s.l.], v. 64, p. 381-389, 2015.

GETACHEW, A. T.; CHUN, B. S. Optimization of coffee oil flavor encapsulation using response surface methodology. LWT - Food Science and Technology, [s.l.], v. 70, p. 126-134, 2016.

GOULA, A. M.; ADAMOPOULOS K. G. A method for pomegranate seed application in food industries: Seed oil encapsulation. Food and Bioproducts Processing, [s.l.], v. 90, p. 639-652, 2012.

GUNSTONE, F. D.; Vegetable Oils in Food Technology: Composition, Properties and Uses. 2. ed. Oxford: Blackwell Publishing/CRC, 2002.

HERNANDEZ, S. G. R.; RIVERA, C.D. ALSEC ALIMENTOS SECOS SAS. Microencapsulated nanoparticles comprise acceptable vegetable oils and proteins, and carriers for pharmaceutical, cosmetic and food line. WO2019025879-A1, 7 Fev. 2019. Disponível em: https://apps.webofknowledge.com. Acesso em: 10 maio 2019.

INPI - INSTITUTO NACIONAL DA PROPRIEDADE INDUSTRIAL. [Base de dados - Internet]. 2019. Disponível em: http://www.inpi.gov.br. Acesso em: 12 maio 2019.

LEHNINGER, T. M.; NELSON, D. L.; COX, M. M. Princípios de Bioquímica. 6. ed. [s.l.]: Artmed, 2014.

LUO, Z; LIU, X.; QIN, X. Univ. South China Technology (UYSC-C). Preparing steady-state edible powder vegetable oil involves preparing buffer with disodium hydrogen phosphate and sodium dihydrogen phosphate, formulating starch into starch milk in buffer solution, gelatinizing in boiling water bath. CN-108936576-A, 7 Dec. 2018. Disponível em: https:/apps. webofknowledge.com. Acesso em: 10 maio 2019.

MAYERHOFF, Z. D. V. L. Uma Análise Sobre os Estudos de Prospecção Tecnológica. Cadernos de Prospecção, Salvador, v. 1, n. 1, p. 7-9, 2008.

MONDELLO, L. et al. Reliable characterization of coffee bean aroma profiles by automated headspace solid phase microextraction-gas chromatography-mass spectometry with the support of a dual-filter mass spectra library. Journal of Separation Science, [s.l.], v. 28, n. 9-10, p. 1.1011.109, 2005.

NESTERENKO, A. et al. A new way of valorizing biomaterials: The use of sunflower protein for $\alpha$-tocopherol microencapsulation. Food Research International, [s.l.], v. 53, p. 115-124, 2013.

NESTERENKO, A. et al. Influence of soy protein's structural modifications on their microencapsulation properties: $\alpha$-Tocopherol microparticle preparation. Food Research International, [s.l.] v. 48, p. 387-396, 2012.

NIKOLOVA-DAMYANOVA, B.; VELIKOVA, R. E.; JHAM, G. N. Lipid classes. Fatty acid composition and triacyglycerol molecular species in crude coffee beans harvested in Brazil. Food Res. Int., [s.l.], v. 31, p. 479-486, 1998. 
PAGE, J. C.; ARRUDA, N. P.; FREITAS, S. P. Crude ethanolic grounds P extract from spent coffee: Volatile and functional properties. Waste Management, [s.l.], v. 69, p. 463-469, 2017.

PATCH, C. S. et al. Clover Corp Ltd. e Clover Corp. Composition, used in e.g. food ingredients and animal feeds, comprises reaction products of mixture comprising aqueous solution of at least one protein e.g. casein and fish oil, and at least one carbohydrate e.g. monosaccharide e.g. glucose. WO2013067603-A1- 16 maio 2013. Disponível em: https://apps.webofknowledge. com. Acesso em: 10 maio 2019.

RAWLINGS, R. M.; PROCTER, D. Blue Wing Corp. Lipid particles microencapsulated in proteinaceous matter - useful in foodstuffs and animal feed supplements, esp. for ruminants. US4217370-A, 12 Ago. 1980a. Disponível em: https://apps.webofknowledge.com. Acesso em: 10 maio 2019.

RAWLINGS, R. M.; PROCTER, D. Blue Wing Corp. Ruminant feed supplement contg. Lipid - microencapsulated in albumin derived from blood or whey. US4216234-A, 5 Ago. 1980b. Disponível em: https://apps.webofknowledge.com. Acesso em: 10 maio 2019.

REINECCIUS, G. A.; YAN, C. Factors controlling the deterioration of spray dried flavourings and unsaturated lipids. Flavour and Fragrance Journal, [s.l.], v. 31, n. 1, p. 5-21, 2015.

SCOPEL, F.; GREGOLIN, L. A. R.; FARIA, L. I. L. Tendências tecnológicas do uso do sisal em compósitos a partir da prospecção em documentos de patentes. Polímeros Ciência e Tecnologia, [s.l.], v. 23, n. 4, p. 514-520, 2013.

SHIA, Y.; SHEN, G.; SUNC, P. The role of infrastructure in China's regional economic growth. Journal of Asian Economics, [s.l.], v. 49, p. 26-41, 2017.

SILVA, V. M.; VIEIRA, G. S.; HUBINGER, M. D. Influence of different combinations of wall materials and homogenisation pressure on the microencapsulation of green coffee oil by spray drying. Food Research International, [s.l.], v. 61, p. 132-143, 2014.

SUN-WATERHOUSE, D.; WANG, W.; WATERHOUSE, G. I. N. Canola Oil Encapsulated by Alginate and Its Combinations with Starches of Low and High Amylose Content: Effect of Quercetin on Oil Stability. Food Bioprocess Technol. [s.l.], v.7, p. 2.159-2.177, 2014.

VAIDYA, S.; BHOSALE, R.; SINGHAL, R. Microencapsulation of cinnamon oleoresin by spray drying using different wall materials. Drying Technology, [s.l.], v. 24, n. 8, p. 983-992, 2006.

WANG, B. et al. Clover Corp Ltd. e Clover Corp. Production of nutritional formulation comprising fatty acid by providing double emulsion of fatty acid within edible oil stream such as vegetable oil, and mixing double emulsion of fatty acid within edible oil stream with aqueous phase. WO2017177283-A1, 19 out 2017. Disponível em: https://apps.webofknowledge. com. Acesso em: 10 maio. 2019.

ZELLER, L. C.; CHANG, R. W. H.; NORBURY, R. J. Minnesota Mining \& MFG CO (MINN-C). Cosmetic compons. - are microencapsulated cosmetic oils, using polymeric thickener additive to produce larger size capsules. EP254447-A, 7 Jul. 1987. Disponível em: https://apps. webofknowledge.com. Acesso em: 10 maio 2019. 


\section{Sobre os Autores}

\section{Julio Page de Castro}

E-mail: julio.castro@ifrj.edu.br

Doutor em Engenharia de Processos Químicos e Bioquímicos pela Universidade Federal do Rio de Janeiro em 2020.

Endereço profissional: Avenida República do Paraguai, n. 120, Sarapui, Duque de Caxias, RJ. CEP: 25050-100.

\section{Carolina Vieira Viêgas}

E-mail: carolquimica@gmail.com

Doutora em Tecnologia de Processos Químicos e Bioquímicos pela Universidade Federal do Rio de Janeiro em 2015.

Endereço profissional: Av. Athos da Silveira Ramos, n. 149. Escola de Química, bloco E, sala E-201, Ilha do Fundão, Rio de Janeiro, RJ. CEP: 21941-909.

\section{Lília Calheiros de Oliveira Barretto}

E-mail: liliacalheiros@gmail.com

Doutora em Engenharia de Processos Químicos e Bioquímicos pela Universidade Federal do Rio de Janeiro em 2015.

Endereço profissional: Rodovia Eng. Jorge Neto, Km 03, s/n, Bairro Silos, Nossa Senhora da Glória, SE. CEP: 49680-000.

\section{Suely Pereira Freitas}

E-mail: freitasp@eq.ufr.br

Doutora em Engenharia Nuclear e Planejamento e Projeto pela Universidade Federal do Rio de Janeiro em 1990. Endereço profissional: Av. Athos da Silveira Ramos, n. 149. Escola de Química, bloco E, sala E-201, Ilha do Fundão, Rio de Janeiro, RJ. CEP: 21941-909. 